106 | InterAção

\title{
MULTILATERALISMO NECESSÁRIO: UMA ANÁLISE DA RESPOSTA NORTE-AMERICANA AO CONFLITO CIVIL NA SÍRIA COMO ESTRATÉGIA DE RATIONAL COOPERATION
}

Amanda Martinazzo Bier ${ }^{1}$

\section{Resumo}

A Síria é palco, desde o início de 2011, de um dos conflitos civis mais sangrentos da história recente. Impulsionada pelos levantes no Oriente Médio que ficaram conhecidos como Primavera Árabe, a população síria pedia por melhores condições de vida e a ampliação dos direitos individuais, além do fim do regime de Bashar Al Assad. Marcado pela violenta resposta do governo, o movimento na Síria logo ganhou a atenção da sociedade internacional. Reconhecido como grande vetor dos valores ocidentais, o governo americano, em consonância com uma estratégia internacional que enfatiza a diminuição do envolvimento do país com questões do Oriente Médio,

\footnotetext{
${ }^{1}$ Graduada no Curso de Relações Internacionais da Universidade Federal de Santa Maria - UFSM (2014).
} 
$107 \mid$ InterAção

optou pelo multilateralismo como resposta aos eventos na Síria. Este trabalho analisa a opção do governo dos Estados Unidos pelo multilateralismo como estratégia de política externa do país para o conflito civil na Síria a partir do conceito de rational cooperation.

Palavras-chave: Cooperação Racional. Política Externa Norte-Americana. Síria.

\begin{abstract}
Since the beginning of 2011, Syria holds within its borders one of the bloodiest civil conflicts of recent history. Triggered by the uprisings in the Middle East that became known as the Arab Spring, the Syrian population asked for better living conditions and individual rights, as for the end of the Bashar Al Assad's regime. Marked by the violence of the government's response, the Syrian uprising soon gained the attention of international society. Known as the great vector of occidental values, the American government, regarding an international strategy that emphasizes the lessen of the involvement of the
\end{abstract}


108 | InterAção

country with Middle Eastern matters, chose multilateralism as the adequate answer to the events unfolding in Syria. This Senior Thesis analyzes the United States' government choice of multilateralism as the foreign policy strategy of the country towards the civil conflict in Syria through the concept of rational cooperation.

Keywords: Rational Cooperation. American Foreign Policy. Syria.

\section{INTRODUÇÃO}

Em março de 2011, a população de uma cidade no interior da Síria saiu às ruas para pedir a libertação de 14 jovens que foram presos por pichar em um muro perto da escola em que estudavam uma frase que fazia alusão à queda do regime de Bashar Al Assad. Em questão de dias, os protestos ganharam força em diversas cidades do país, pedindo por melhores condições de vida à população, liberdades individuais e direitos políticos. Parte de uma série de levantes ocorridos no Oriente Médio a partir de dezembro de 2010, quando um vendedor de rua ateou 
109 InterAção

fogo a seu próprio corpo como sinal de protesto na Tunísia, o movimento na Síria encontrou violenta repressão por parte do governo, transformando-se em um conflito civil que se estende até os dias de hoje, tendo já ultrapassado a marca dos cem mil mortos (ACNUDH, 2013).

Por sua duração e violência, o conflito civil na Síria logo se transformou em um dos maiores desafios de política externa enfrentados por Barack Obama. Idealizador de uma estratégia nacional preocupada com a melhora da imagem dos Estados Unidos no mundo, a defesa dos ideais liberais e a diminuição do envolvimento do país em questões no Oriente Médio, Obama precisou encontrar formas de conciliar o aparente "dever moral" de ação americana com uma situação interna completamente desfavorável a um envolvimento direto dos Estados Unidos no conflito na Síria.

Em um dos únicos episódios em décadas de política externa americana ${ }^{2}$ para o Oriente Médio, Obama

\footnotetext{
2 Apesar de a América e a América do Norte compreenderem países que não os Estados Unidos, neste trabalho se utilizará o gentílico americano e norte-americano como sinônimos de estadunidense.
} 
110 | InterAção

depositou esforços e esperanças em organismos e fóruns internacionais. O governo americano, que foi severamente criticado, interna e internacionalmente por sua falta de postura clara em relação aos levantes no mundo árabe em geral, apostou no multilateralismo como forma de conciliar a necessidade de resposta aos eventos que se desenrolam na Síria e a notória dificuldade que enfrentaria uma opção pela intervenção militar unilateral direta no país.

O violento desenrolar do conflito foi agravado ainda pela falta de uma resposta ágil e adequada da sociedade internacional, isto porque uma abordagem equivocada à questão síria, país de enorme importância estratégica em termos de estabilidade na região, acarretaria em problemas ainda mais notórios.

No international actor really wants to face the risk of an unstable and fragmented Syria such as might follow the collapse of the regime. For their part, American officials have believed that a collapse of the Syrian regime would be followed by one of two likely scenarios. On the one hand, there is the possibility of expanded sectarian violence, ethnic violence, or both [...]. Further muddying the waters with American policy makers 
$111 \mid$ InterAção

is the belief that only a strong autocrat at the helm in Syria can make the highly unpopular decision to sign a peace treaty with Israel (GELVIN, 2012).

Com uma política de resposta aos levantes que ficaria conhecida como "hands-off policy", desde o início os Estados Unidos deram poucos sinais de probabilidade de um envolvimento mais sério do país. Ainda que com conhecidas dificuldades práticas, desde o início de seu governo, um dos principais objetivos da política externa de Obama é o de "make peace" com o Oriente Médio, e melhorar a imagem dos Estados Unidos no mundo, encerrando os dois grandes envolvimentos do país na região, tanto no Afeganistão quanto no Iraque. Apesar de não descartar o uso de poder militar americano no Oriente Médio, um dos grandes pontos de inflexão da política externa de Obama para a de seu predecessor é a determinação de não envolver militarmente os Estados Unidos em conflitos de longa duração em que não se percebam claros interesses americanos ou lhes falte apoio de países aliados (SANGER, 2013). 


\section{InterAção}

A falta de resposta de Obama ao desenrolar dos eventos na Síria inflamou críticas em importantes segmentos da oposição republicana a seu governo. A falta de ação é vista como sinal de fraqueza do país, além de uma má coordenação da política externa, que, mais do que não agir, não consegue deixar claro para o mundo qual é a posição americana em relação ao conflito.

What are America's interests in the Middle East? How will we protect them as old regimes fall and new ones try to take shape? Can we influence outcomes? How should we prepare for the rise of Islamism, civil wars, state failures, reversals, and recrudescence of dictatorship? We need answers to these questions and a strategy for realizing the best, avoiding the worst, and protecting our interests in the process. America cannot and should not decide the fate of the Middle East, but it should be clear about its stakes in the region, and not shy away from efforts to at least nudge events in more favorable directions as a critical world region faces momentous choices. A "lean back and wait" posture toward unfolding events will not be enough a series of reactions and tactical maneuvers do not amount to a strategy. A strategy requires having a clear view of our interests and of how to realize them by influencing as best we can the dynamics that are shaping 
$113 \mid$ InterAção

the region. [...] President Obama's approach to the Middle East has been distant from the outset. He has wanted to improve America's image in the Muslim world and feels the best way to do this is to end America's unpopular wars there. His modus operandi has been disengagement: end existing commitments, foremost among them Iraq and Afghanistan, and avoid new entanglements (NASR, 2013).

Para um grande número de republicanos no governo, a obstinação americana em não se envolver nos conflitos no Oriente Médio tende ainda a gerar um vácuo de poder na região, abrindo espaço para que outras potências desempenhem um papel de liderança. Com uma enorme importância estratégica para a China, o Oriente Médio tem sido foco de atuação em política externa para o país já há alguns anos. A crítica à atuação americana em relação à Síria é parte de uma grande crítica à política externa de Obama voltada para o Oriente Médio. Mais do que a opção pela retirada ou não do país da região, existe dissenso ainda sobre a forma como essa retirada deve acontecer, muitos percebem a complexidade gerada a partir do envolvimento americano, clamando por uma retirada segura e responsável, garantindo segurança, 
114 | InterAção

estabilidade e a manutenção dos valores democráticos ocidentais àqueles países que tiveram sua soberania violada.

Indyk, Liberthal e O'Hanlon (2012) acusam Obama de assumir uma postura marcadamente realista depois de ter chegado ao poder. Para os autores, muito da dificuldade de Obama em assumir uma postura adequada frente à Primavera Árabe resulta do abandono de seus ideais, grandes visões e esperança que marcaram sua campanha para a adoção de uma política externa preocupada, em última análise, com a manutenção da segurança dos Estados Unidos em um mundo de grandes e diversas ameaças.

Logo no início dos levantes, ainda nos primeiros meses de 2012, discursos genéricos de Obama sobre o suporte aos movimentos em favor da democracia cederam lugar a uma postura pragmática sobre os reais interesses dos Estados Unidos na região, acompanhada por um intenso suporte da população americana pelo não envolvimento do país em maiores conflitos no Oriente Médio. A defesa dos "valores americanos" ficaria subordinada a uma cuidadosa análise dos custos para o 
$115 \mid$ InterAção

país, e o fracasso das invasões no Afeganistão e no Iraque permeavam o discurso de Obama que lembrava a

dificuldade da imposição da democracia, que deveria, segundo ele, ser um processo conquistado pelo povo, fundado em sólidas bases.

When he took office, Obama did not want to engage in any war. His goal was to raise the threshold for military action much higher than it had been since the end of the cold war, when Desert Storm, Somalia, Kosovo, Afghanistan and Iraq and other lesser interventions formed an ongoing patter in U.S. foreign policy. Whatever the justifications for any of these, Obama saw the United States as being overextended by the tempo of war. He intended to disengage from war and to play a lesser role in general in managing the international system. At most, he intended to be part of the coalition of nations, not the leader and certainly not the lone actor. [...] He clearly regarded Syria as not meeting the newly raised standard. It was embroiled in a civil war, and the United States had not been successful in imposing its will in such internal conflicts. Moreover, the United States did not have a favorite in the war. Washington has a long history of hostility toward the al Assad regime. But it is also hostile to the rebels, who - while they might have some constitutional democrats 


\begin{abstract}
116 | InterAção
among their ranks - have been increasingly falling under the influence of radical jihadists. The creation of a nation-state governed by such factions would recreate the threat posed by Afghanistan and leading to Sept. 11, and do so in a country that boarders Turkey, Iraq, Jordan, Israel and Lebanon. Unless the United States was prepared to try its hand again once again at occupations and nation-building, the choice for Washington had to be "none of the above" (FRIEDMAN, 2013).
\end{abstract}

Na manhã de 21 de agosto de 2013, uma ofensiva do governo sírio contra os rebeldes na região agrícola de Goutha, nas proximidades de Damasco, utilizando o que depois ficou comprovado serem armas químicas, aumentou sobremaneira a expectativa da sociedade internacional como um todo sobre uma eventual intervenção direta americana. O governo sírio enfim, cruzou a "red line" colocada pelo presidente americano em seus discursos sobre as atrocidades que vinham acontecendo no país. $\mathrm{O}$ ataque do governo sírio teve ainda um significado ideológico fundamental para a administração de Obama.

All American administrations have a tendency to think ideologically, and 
$117 \mid$ InterAção

there is an ideological bent heavily represented in the Obama administration that feels that U.S. military power ought to be used to prevent genocide. This feeling dates back to World War II and the Holocaust, and became particularly intense over Rwanda and Bosnia, where many believe the United States could have averted mass murder. Many advocates of American intervention in humanitarian operations would oppose the use of military force in other circumstances, but regard its use as a moral imperative to stop mass murder (FRIEDMAN, 2013).

Ao contrário do que era esperado por parte da sociedade internacional ou mesmo por analistas de política externa americana, entretanto, os Estados Unidos, ainda que tenham passado a considerar algum tipo de retaliação militar aos ataques do governo sírio, continuaram buscando apoio internacional para suas ações. Obama procurou contar com a legitimação das Nações Unidas, por exemplo, desde o início do conflito, para a adoção de sanções econômicas mais severas, em consonância com os demais países membros, marcadamente os membros do Conselho de Segurança. 
118 | InterAção

Historicamente, os Estados Unidos são reconhecidos pela sociedade internacional como o grande vetor dos chamados valores ocidentais. Quando da eclosão dos primeiros conflitos da primavera árabe e no caso da Síria especificamente, a sociedade internacional esperava um posicionamento concreto do país, que em sua história envolveu-se diversas vezes em conflitos civis sob a bandeira da promoção da democracia e das liberdades individuais. Além desse papel histórico, a complexa relação entre os Estados Unidos e o Oriente Médio que se desenrolou nas últimas décadas fez aumentar ainda mais as expectativas da sociedade internacional.

Contribuem ainda para esse "moral duty" americano duas grandes questões de caráter ideológico. A primeira delas acompanha os governos americanos desde o final da Segunda Guerra Mundial e diz respeito à determinação do país, desde o final desse conflito, a livrar o mundo das chamadas armas de destruição em massa (ADMs). É política perene dos governos americanos desde então localizar, reunir e destruir essas armas. O segundo fator ideológico também acompanha os EUA desde o final 
119 InterAção

da Segunda Guerra, mas é particularmente expressivo dentro do governo democrata de Barack Obama. Deflagrada pelas atrocidades do Holocausto que marcaram a Europa e a sociedade internacional como um todo e inflamada pelos episódios em Ruanda e na Bósnia, existe uma corrente bastante expressiva politicamente nos Estados Unidos que acredita que, em situações em que possa prevenir assassinatos em massa, o exército americano, mais do que capacidade e legitimidade, tem o dever de agir.

A opção americana pela via multilateral de resolução de questões no Oriente Médio destoa do que foi feito em relação à região em termos de política externa americana nos últimos anos, e é reflexo de condições sistêmicas, bem como domésticas, somadas a uma opinião pública, particularmente a americana, mas também a da sociedade internacional como um todo, em sua maioria desfavorável a um novo engajamento do país em relação àquela região. A proposta desse artigo é que possamos analisar brevemente importantes condições internas e sistêmicas que impõem grandes dificuldades a uma intervenção unilateral militar americana na Síria e ajudam 
120 | InterAção

portanto a justificar a opção do país pelo multilateralismo como forma de resposta ao conflito civil sírio. A hipótese é que essas condições desfavoráveis, somadas ao aparente "dever moral de ação", justificam a opção pelo multilateralismo como uma estratégia de rational cooperation, conforme entendida pela Interdependência Complexa. O presente artigo é fruto de intensa revisão bibliográfica, tanto de importantes periódicos voltados à análise de política externa americana, como também de consagrada literatura acerca da Teoria da Interdependência Complexa e da história da política externa americana. Foram analisados ainda importantes páginas especializadas em análise estratégica de política externa americana, além de relatórios das Nações Unidas sobre a crise na Síria.

\section{I - FOREIGN POLICY BEGINS AT HOME:DESAFIOS INTERNOS À PROJEÇÃO INTERNACIONAL DOS ESTADOS UNIDOS}

No início de 2013, o presidente do Council on Foreign Relations desde 2003, Richard N. Hass, publicou 
$121 \mid$ InterAção

um livro do qual emprestamos o título para este capítulo. Foreign Policy Begins at Home: The Case for Putting America's House in Order é um livro dedicado a compreender diversas debilidades internas que, segundo o autor, têm implicado em uma queda na performance dos Estados Unidos em suas atuações no cenário internacional.

Já na introdução ele procura deixar bastante claro que não é adepto aos discursos sobre o declínio americano e que, apesar de acreditar que os Estados Unidos devam voltar suas atenções para problemas domésticos, é contrário ao isolacionismo. Os Estados Unidos continuam sendo a mais poderosa nação do mundo, com um importante papel a desempenhar dentro do sistema internacional, cujas decisões e ideias influenciam as decisões dos demais atores internacionais mais do que quaisquer outras. Ocorre que, dadas as suas potencialidades, o país vem tendo um desempenho medíocre em suas relações exteriores, caracterizados por uma falta de clareza sobre seus reais objetivos.

The biggest threat to America's security and prosperity comes not from abroad but from within. The United States has jeopardized its 


\section{InterAção}

ability to act effectively in the world because of runway domestic spending, underinvestment in human and physical capital, an avoidable financial crisis, an unnecessarily slow recovery, a war in Iraq that was flawed from the outset and a war in Afghanistan that became flawed as its purpose evolved, recurring fiscal deficits and deep political divisions. For the United States to continue to act successfully abroad, it must restore the domestic foundations of its power. Foreign policy needs to begin at home, now and for the foreseeable future (HAAS, 2013).

Restoration é o termo de que se utiliza o autor para se referir à estratégia que segundo ele deveria permear as decisões de política externa dos Estados Unidos. É viável em um mundo como o atual, segundo o autor, que não oferece grandes ameaças aos Estados Unidos. Deveria deixar de ter suas atenções tão voltadas ao Oriente Médio e preocupar-se em moldar as escolhas de outros Estados importantes. Sua atenção e seus esforços deveriam estar melhor distribuídos entre as várias regiões do mundo que carregam grandes interesses americanos, e, por fim, seria uma estratégia que reavaliaria a forma de projeção de poder, dando menos ênfase a instrumentos militares de poder à medida em que o aspecto econômico passa a 


\section{InterAção \\ desempenhar um papel ainda mais fundamental na política externa dos Estados Unidos (HAASS, 2013).}

Restoration is also entirely consistent with American leadership. I would actually go beyond that; it is a prerequisite for effective American leadership. Only by putting its house in order will the United States have the resources needed to act in the world in a meaningful way, set an example others will be tempted to follow, and signal a latent capacity that will discourage would-be rivals and adversaries from crossing the line. Leadership, just to be clear, is not to be confused with unilateralism, as leadership requires partners if it is to have any meaning. There may be occasions for acting alone, but they will be the exception, especially when the resource costs are great or the nature of the struggle requires widespread participation, which is almost always the case when the challenge is a global one. The specifics of leadership can and should change from situation to situation, depending on the interests at stake, what others are prepared to do, the nature of what is required, and the potential of the United States on its own to do some or all of what is required if the contemplated action is to have the desired effect. Depending on these considerations, leadership can take place from in front, behind, or 
124 | InterAção

somewhere in between (HAASS, 2013).

Com a complexificação da agenda internacional, característica da interdependência complexa ${ }^{3}$, a capacidade militar cada vez mais deixa de fazer jus ao papel de grande referência em termos de poder como colocado pela Teoria Realista. Nye (2012) coloca o poder nas relações entre os Estados nos dias de hoje como um tabuleiro de xadrez tridimensional ${ }^{4}$, tendo o tabuleiro do

${ }^{3}$ Aqui entendemos a interdependência complexa como um modelo ideal do Sistema internacional, compreendida a partir da Teoria da Interdependência Complexa, uma das novas abordagens das relações internacionais, que tem como dois grandes expoentes Joseph Nye e Robert Keohane. Desenvolvida na década de 1970 e 1980, essa teoria busca oferecer respostas aos novos desafios das relações internacionais que não vinham sendo respondidos de forma adequada pelas teorias clássicas. Keohane e Nye entendem a interdependência como um estado ideal do sistema internacional, que vai além da simples dependência e conexão que liga os atores internacionais dentro de um complexo sistema de interações. A interdependência pressupõe dependência mútua, agregada a determinado efeito, ou seja, custos recíprocos entre os Estados, decorrentes dessa dependência. Esse cenário ideal de organização do sistema internacional, segundo os autores, é capaz de aproximar-se da realidade de forma mais satisfatória do que o modelo colocado pelos realistas em um grande número de situações.

4Joseph Nye (2012) compara as relações de poder entre os Estados na atualidade a um tabuleiro de xadrez tridimensional. No primeiro plano estariam as relações militares, onde os Estados Unidos ainda ocupam e tendem ainda a ocupar por muito tempo o papel de superpotência, sem qualquer Estado capaz de Ihes fazer frente sozinho. 0 segundo tabuleiro seria 0 das relações econômicas, onde os Estados Unidos, ainda que superiores em relação aos demais Estados, já enfrentam acirrada competição de outros países como a China ou ainda blocos econômicos como a União Europeia. Por fim, 0 terceiro tabuleiro seria 0 das chamadas relações transnacionais, onde ocorrem intensas trocas entre governos dentro de países, grandes corporações, partidos políticos, milícias, e a própria sociedade civil. Neste terceiro tabuleiro, segundo Nye, não faz sentido pensarmos em qualquer tipo de hegemonia ou supremacia de um Estado em relação aos demais. 
$125 \mid$ InterAção

meio, que compreende as relações econômicas, cada vez mais importância à medida em que é percebido como eficiente moeda de barganha em um mundo em que o poder militar consegue responder a um número cada vez menor de desafios. Quando pensamos o poder nas relações internacionais em termos de interdependência assimétrica ${ }^{5}$, a economia veste-se de enorme importância à medida em que um Estado com maiores poderes econômicos em relação aos demais é geralmente menos vulnerável a determinada alteração sistêmica.

Para os Estados Unidos, mais do que poder relativo em relação aos demais, sua sanidade econômica é fator de credibilidade e reputação frente aos demais atores do sistema internacional. Tendo sido o grande arquiteto do sistema econômico e financeiro internacional como hoje o compreendemos, os Estados Unidos têm na força de sua economia e na crença na estabilidade de sua moeda

${ }^{5} \mathrm{Em}$ um contexto de interdependência complexa, Keohane e Nye entendem a interdependência assimétrica como uma forma de poder. Explicam os autores que, em uma relação de dependência mútua, 0 ator que tiver menos a perder com 0 término daquela relação tem um "significativo recurso político", "because changes in the relationship (which the actor may be able to initiate or threaten) will be less costly to that actor than to its partners" (KEOHANE; NYE, 1977). 
um dos mais importantes pilares de sustentação da sua peculiar posição dentro do sistema de Estados.

Nas eleições presidenciais de 2012, a saúde da economia do país foi um dos principais temas de debate entre o republicano John McCain e Barack Obama. Com um grave déficit interno, baixos índices de emprego e a maior dívida externa do mundo, questões econômicas foram pauta mesmo quando os questionamentos pairavam em torno da atuação externa do país. Durante a campanha eleitoral, foi consenso entre os dois candidatos, com diferenças em termos de intensidade, de que o país deveria voltar-se para seus problemas internos para criar uma estratégia eficiente de atuação internacional.

[...] the very assumption that overseas challenges are distinct from those at home is outdated. In a global economy, every national priority, from the stability of the financial system to the safety of the food supply, is influenced by what happens beyond America's borders. The discussion of domestic issues in the context of national security is long overdue. [...] During the $20^{\text {th }}$ century, the U.S. rise to global dominance was driven less by its military strength than by the dynamism of its economy. The key to America's victories in World War II and the Cold War is that 
$127 \mid$ InterAção

we had our economy do the "heavy lifting". That's always been the secret of American strategic success. [...] That strategic edge has eroded, however, because of a decade of middling growth and ballooning deficits - the result of 2008 financial crisis, huge increases in domestic spending, and the costs of two foreign wars. The cumulative effect is a much worse, far more vulnerable position than we've ever had before (RATNESAR, 2012).

O déficit do governo americano, compreendido como a diferença entre aquilo que o governo arrecada com taxas e impostos, por exemplo, e seus gastos, é avaliado hoje em 16 trilhões de dólares, quase seis vezes o valor do déficit há 10 anos. Segundo Haass, esse aumento pode ser explicado pelos cortes de impostos promovidos pelo governo americano em 2001 e 2003, o aumento do governo com gastos sociais, e o longo envolvimento do país com as guerras no Iraque e no Afeganistão, que correspondem a cerca de $15 \%$ do déficit anual do país. Todos esses fatores agravados substancialmente pela crise econômica de 2008 (HAASS, 2013).

O grande problema, segundo Haass, não é a dívida em si, mas sim a quantidade de dinheiro gasta para 
financiar essa dívida, desviando potenciais investimentos em áreas crucias que estão hoje em declínio, como a educação ou a infraestrutura, por exemplo, ambos importantes setores que influenciam na competitividade internacional do país (HAASS, 2013).

Just financing all this debt threatens to absorb a significant percentage of the funds that would otherwise be available for education, research and infrastructure: Increasingly, the United States will be forced to eat its seed corn to pay for its past and present. American ability to compete successfully in an increasingly competitive global economy will suffer. [...] Fiscal, economic and political failures at home are placing at risk the continued ability of the United States to exert the global influence that it could and should have (HAASS, 2013).

Além do problema fiscal, os Estados Unidos contam ainda com um baixo crescimento econômico. Desde 2001, o país tem uma média de crescimento inferior a 3\% ao ano, segundo dados do Banco Mundial, atingindo valores negativos em 2008 e 2009 (WORLD BANK, 2012). Esse baixo crescimento econômico tem causas estruturais, como a disseminação tecnológica, diminuindo o número de empregos no país, bem como o aumento da 
$129 \mid$ InterAção

competitividade internacional, junto com outros fatores decorrentes da intensificação do fenômeno do globalismo; e também conjunturais, como a crise econômica de 2008. Apesar de já apresentar sinais de recuperação, a economia americana ainda sofre com consequências da crise que teve seu início no setor imobiliário.

The consequences of prolonged low growth (and the continued stagnation or, in many cases, fall in the incomes of many American households) would be serious and potentially dire. Fewer resources could be tapped for international involvement; the US role in the world would necessarily be more limited than interests and conditions would warrant. The American public would become more preoccupied with national rather than international challenges. Friends and foes alike would have to recalculate based on what the United States could be expected to do. The appeal of the US political and economic model would also be distinctly limited. The net result would be a world less peaceful, less free, and less prosperous. [...] A return to relatively high rates of growth is essential if this country is to maintain its social cohesion and to have the resources and the outlook it will need to lead the world and provide for its citizens (HAASS, 2013). 


$$
130 \text { | InterAção }
$$

Os diversos desafios econômicos enfrentados pelos Estados Unidos dificultam a justificação do envolvimento do país em um conflito civil além de suas fronteiras. Apesar do apelo ideológico pela questão da democracia e do respeito aos direitos humanos, duas grandes bandeiras americanas e ocidentais, a Síria tem relevância estratégica em uma região da qual o atual governo americano almeja, aos poucos, distanciar-se. Além disso, o histórico de envolvimentos do país em conflitos dessa natureza mostra que, mais do que depor o atual governo, os Estados Unidos muito provavelmente teriam de engajar-se no processo de reestruturação da sociedade civil e manutenção do novo governo, gerando gastos ainda maiores.

A dificuldade econômica interna é parte da segunda justificativa para a dificuldade da intervenção unilateral dos Estados Unidos na crise da Síria. Ciente das dificuldades internas que enfrenta o país e esperando políticas eficientes do atual governo, a opinião pública6, inflamada ainda pelo fantasma das duas guerras

\footnotetext{
${ }^{6}$ Em 1961, o cientista político Americano Vladimer Orlandus Key definiu opinião pública como "opinions held by private persons which governments find it prudente to heed” (KEY, 1961).
} 
$131 \mid$ InterAção

malsucedidas em que o país se envolveu na região, é veementemente contrária ao envolvimento direto do país na guerra civil na Síria.

Dentro das relações internacionais contemporâneas, a opinião pública, ainda que as diferentes teorias tenham dificuldade para chegar a um consenso sobre sua classificação como ator internacional ou não, é revestida de grande importância. Com a disseminação dos governos democráticos e a crescente percepção de que decisões de seus governos em termos de política externa afetam diretamente as suas vidas e também a de outras sociedades ao redor do mundo, questões internacionais têm ganhado espaço dentro do interesse e do debate entre os cidadãos em geral. Seja elegendo seus representantes ou ainda pressionando o governo, a opinião pública tem hoje, sem dúvida, grande capacidade de influência nas decisões de política externa do mais relevante ator das relações internacionais: o Estado. questões internacionais deve ser percebida sob um duplo aspecto: primeiramente, como um vetor 


\section{InterAção}

apreendido, com maior ou menor sensibilidade, pelos outros atores internacionais, os quais tendem a incorporar as demandas da opinião pública fazendo-a participar da definição do conteúdo da ação internacional dos atores tradicionais. É necessário enfatizar que a opinião pública não deve ser confundida com os grupos de pressão e com as organizações não-governamentais. Aqueles, tradicionalmente, e estas mais recentemente, interagem internacionalmente de forma autônoma ou por meio de outros atores. A opinião pública deve ser considerada, ontologicamente, como uma das expressões da sociedade civil desorganizada. Ela não dispõe de autonomia e a emotividade que marca sua ação internacional é inimiga do possível, não lhe concedendo o recuo necessário que sustenta a racionalidade da ação dos outros atores. Portanto, sua influência sobre os acontecimentos internacionais somente ocorre de forma pontual por meio dos atores tradicionais. [...] A segunda forma de manifestação da opinião pública é recente e decorre da ação denominada sociedade civil organizada, sobretudo pelas redes de telecomunicações. Pode-se questionar a existência de uma verdadeira sociedade civil internacional organizada, mesmo que ela estivesse assentada unicamente nos regimes pluralistas, pois seria indispensável que, além da constância e da continuidade, ela dispusesse de meios para fazer frente aos atores 
$133 \mid$ InterAção

tradicionais das relações
internacionais, em particular ao
Estado. Todavia, parece claro que se
presencia a gestão de um ator
incontrolável das relações
internacionais, formatando-se em
sociedade civil internacional, com um
aumento exponencial dos utilizadores
da rede Internet (SEITENFUS, 2004,
grifo do autor).

Apesar de uma das motivações da decisão dos Estados Unidos pela não intervenção direta no caso da Síria e da grande estratégia de política externa de Obama como um todo ser a recuperação da imagem americana frente a esta que Seitenfus se refere como sociedade civil internacional, nosso estudo tem enfoque na sociedade civil desorganizada, que atua mormente dentro das fronteiras nacionais, e consegue agir internacionalmente graças a sua influência nas decisões dos tradicionais atores das relações internacionais.

Dentro da Teoria da Interdependência Complexa, a opinião pública exerce sua influência tanto no primeiro dos três tabuleiros de Nye sobre o poder nas relações internacionais contemporâneas, no qual o Estado ainda é ator unitário, ainda que em teoria, único detentor legítimo da possibilidade de uso de força militar, através de sua 
influência e participação política; quanto no tabuleiro inferior, das relações transnacionais, que abrangem uma grande diversidade de atores, capazes de exercer influência internacional de diferentes formas. A grande importância da opinião pública para a teoria, entretanto, reside na socialização da política externa, fruto da complexa rede de interações entre os Estados, característica da sociedade internacional contemporânea, que faz surgir nos cidadão a percepção da interdependência, dos múltiplos efeitos de ações isoladas dos Estados, revestindo-a de importante papel dentro das relações internacionais desde a consolidação da democracia como forma de organização política.

[...] a emergência da opinião pública como um ator de relações internacionais, que deve muito de seu surgimento exatamente ao papel crítico frente ao processo de globalização e frente à atuação dos Estados Unidos pelo mundo, é uma expressão cabal da possibilidade de eclosão de uma sociedade civiltransnacional que elabora demandas inclusive frente a temas como a guerra e a paz, questões tradicionalmente de domínio reservado aos decision-makers da política externa. [...] O surgimento da opinião pública como um ator nas 
$135 \mid$ InterAção

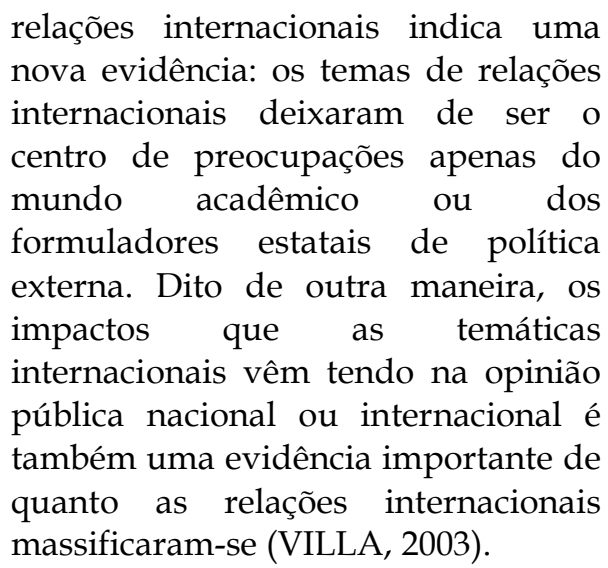

Entre os dias 6 e 8 de setembro deste ano, o periódico The New York Times, em parceria com a CBS rede de notícias, conduziu uma pesquisa sobre as visões da opinião pública americana acerca de uma intervenção do país na Síria através da agência SSRS of Media. Quando questionados se os Estados Unidos deveriam assumir uma posição de liderança em relação a outros Estados do mundo ao tentar resolver conflitos internacionais, $62 \%$ dos entrevistados responderam que não, 34\% responderam que sim, e 5\% não tiveram opinião. $72 \%$ dos entrevistados acreditam que os Estados Unidos não deveriam intervir em questões internas de outros países, mesmo quando a razão da intervenção seja relacionada à implantação da democracia em outros 
136 | InterAção

países. 79\% acreditam que o governo americano ainda não logrou explicar de forma clara quais são seus reais interesses em relação ao conflito na Síria, e 66\% acreditam que uma eventual ação militar americana na Síria seria um longo e custoso investimento (SSRS, 2013).

A pesquisa mostra uma clara inclinação da população pela não intervenção direta dos Estados Unidos, tanto pelos custos econômicos quanto pela crença de que uma eventual intervenção faria eclodir outros conflitos em países vizinhos. Quando questionados sobre o efeito de uma intervenção nos países vizinhos, 66\% responderam acreditar que uma intervenção americana teria grandes chances de desencadear novos conflitos na região, 21\% responderam que uma intervenção poderia, de alguma forma, desencadear novos conflitos, e apenas $3 \%$ responderam que uma ação americana na Síria não teria qualquer chance de desencadear novos conflitos (SSRS, 2013).

Mais do que uma opinião contrária à intervenção no caso específico da Síria, a pesquisa mostrou ainda uma forte predileção da população pela não intervenção americana em assuntos de outros países de forma geral, 
$137 \mid$ InterAção

refletindo aquilo que foi discutido nos primeiros parágrafos deste capítulo sobre a necessidade de os Estados Unidos voltarem suas atenções, ainda que por um determinado período, para seus problemas internos.

A broad majority of Americans, exhausted by nearly a dozen years of wars and fearful of tripping into another one, are opposed to a military strike on Syria, even though most say they think Syrian forces used chemical weapons against civilians, according to the latest New York Times/CBS News poll. [...] The poll underscores a steady shift in public opinion about the proper American role in the world, as fatigue from the wars in Iraq and Afghanistan has made people less open to intervening in the world's trouble spots and more preoccupied with economic travails at home. [...] In the Syrian crisis, 6 in 10 Americans oppose airstrikes, according to the poll, with similar majorities saying they fear military action could enmesh the United States in another long engagement in the Middle East and would increase the terrorist threat to Americans. [...] But the antipathy to foreign engagement extends beyond the current crisis. Sixty-two percent of the people polled said the United States should not take a leading role in trying to solve foreign conflicts, while only 34 percent said it should. In April 2003, a 
138 | InterAção

month after American troops marched into Iraq, 48 percent favored a leading role, while 43 percent opposed it (LANDLER; THEEBRENAN, 2013).

A opinião pública, mais do que a influência habitual sobre os tradicionais atores estatais, exerce no governo de Obama função ainda mais pujante. Eleito, entre outros fatores, por suas promessas de mudança e revisão do papel dos Estados no mundo, principalmente em termos de ações do país voltadas ao Oriente Médio, o governo democrata precisa dedicar peculiar atenção aos anseios da opinião pública. Em meio a pressões da população pela não intervenção e às críticas, mormente de setores republicanos mas também de eixos democráticos do governo sobre a falta de uma política clara sobre a Síria e o medo da imagem de falta de força do país, Obama tem em suas mãos talvez o maior desafio em termos de política externa de sua gestão e, ao contrário da ação unilateral que o mundo esperava, situações internas do país tornaram sensata a escolha pela via multilateral dos regimes internacionais. 
$139 \mid$ InterAção

No dia 31 de agosto, pouco mais de uma semana depois dos ataques do governo sírio com armas químicas contra a população, Barack Obama falou à população americana que era a hora de uma intervenção militar dos Estados Unidos no país. Desde o início do conflito, Obama definiu a utilização de armas químicas pelo governo como uma "red line", fator que obrigaria os EUA a agirem, por questões morais. Muitos especialistas americanos hoje defendem que Obama determinou essa "linha", que as forças sírias não poderiam ultrapassar justamente porque acreditou que o governo jamais a ultrapassaria.

Na manhã do dia 21, 1400 rebeldes foram mortos pelo governo sírio, segundo dados do governo americano. A suspeita do uso de armas químicas foi confirmada dias depois através de uma comissão da ONU enviada ao país. O mundo já esperava a opção americana pela intervenção militar. O que ocorreu, entretanto, foi que no dia 31, junto com o discurso de Obama ao povo americano sobre a necessidade da intervenção, veio a notícia de que o país só agiria militarmente depois da aprovação da intervenção pelo Congresso do país. 


$$
140 \text { | InterAção }
$$

A legislação americana delega ao presidente a capacidade de autorizar intervenções como a proposta por ele sem a necessidade de autorização do Congresso. A manobra do presidente foi percebida com ceticismo por especialistas em política internacional e ainda por outros chefes de Estado, temerosos de que os Estados Unidos, postergando a prometida intervenção militar, passem para a Síria e outros países, principalmente no Oriente Médio, a imagem de um país fraco e sem políticas claras para a região. A votação no Congresso, agendada a princípio para o dia 9 de setembro, foi postergada a pedido de Obama, que pediu um tempo aos congressistas para que fosse verificada a viabilidade da saída diplomática ao problema sírio arquitetada pelo governo Russo.

Apesar de se recusar a responder perguntas sobre o futuro da intervenção americana na Síria caso o projeto seja negado pelo Congresso, a insistência do país pela busca de aliados e legitimação por organismos ou fóruns internacionais apontam para a improbabilidade de uma ação direta unilateral dos Estados Unidos. Além das duas condições internas trazidas no subcapítulo anterior para demonstrar a dificuldade da ação unilateral dos EUA, 
$141 \mid$ InterAção

nosparágrafosque seguem exploraremos brevemente duas condições sistêmicas que explicam a obstinação americana a não agir unilateralmente.

A primeira delas diz respeito à dificuldade da ação militar americana. Obama já deixou claro que a intervenção militar teria caráter pontual e limitado, visando em última análise eliminar o arsenal químico de Assad. Em um discurso no dia 26 de agosto deste ano, o secretário de Estado americano John Kerry declarou que o objetivo principal de uma eventual intervenção militar na Síria seria a de obrigar o regime de Assad a negociar com a sociedade internacional.

If Obama obtains congressional approval, America will most likely launch a strike on the Syrian regime that, Washington insists, will be "limited". Exactly what "limited" means in this context cannot be clarified. American officials have discussed a potential strike lasting for only a few days with the proposed purpose not to bring about regime change, but rather to act as a deterrent against the regime's re-using chemical weapons again. It would be executed through guided missiles and aircraft, and would not require "boots on the ground". The truth is that air strikes, 
142 | InterAção

no matter how protracted or brief, have never brought down a regime on their own. The question now is: how will the American strike, however large or extensive, damage regime bases, storehouses and airfields, and impact the command and control capacities of the regime forces? (ALJAZEERA, 2013).

Com armas químicas estocadas em diversos locais no país, segundo o relatório da comissão enviada à Síria pela ONU, os Estados Unidos teriam dificuldade para destruir essas armas em sua totalidade sem uma ação em solo, como é a proposta original. O envio de tropas só faria aumentar tanto os gastos do país, como a reprovação da opinião pública à intervenção americana. Mesmo que todas as armas fossem encontradas, restam ainda dúvidas sobre o real impacto da destruição do arsenal químico para o regime de Assad e o desenrolar do conflito civil. A ONU confirmou a morte de pouco mais de 1.400 pessoas pelo uso de armas químicas no episódio do dia 21 de agosto. O número de vítimas do conflito desde seu início em 2011, entretanto, ultrapassa a marca dos 100.000. Existe portanto uma grande variedade de formas de violência sendo exercidas contra a população, fazendo surgir 
$143 \mid$ InterAção

dúvidas sobre a real efetividade da intervenção americana na forma como está arquitetada.

Existem atualmente três tipos de intervenção americana que podem tomar lugar na Síria, de acordo com especialistas em estratégia internacional, todas elas contando com o apoio de países aliados. A primeira seria um ataque punitivo, bastante limitado, atingindo alguns alvos específicos de controle e comando sírio. O ataque, que teria baixo custo para os Estados Unidos, daria credibilidade aos aliados ocidentais, punindo suas lideranças militares. Bashar Al Assad provavelmente não seria alvo, já que a morte do ditador envolveria ainda mais as potências ocidentais no conflito. “The purpose of a punitive strike would be to dissuade the Al Assad regime from the further use of chemical weapons in the civil war without crippling the Syrian regime himself" (STRATFOR, 2013).

A segunda alternativa de ação militar seria não só desencorajar o uso futuro de armas químicas, mas minar a capacidade do regime de usá-las. Além dos centros de comando e controle militar do regime, seriam alvo 
144 | InterAção

também as três principais formas pelas quais o governo sírio faz a entrega de suas armas químicas: a força aérea, mísseis balísticos e artilharia. Um ataque definitivo a estes três segmentos faria necessário um maior investimento por parte dos EUA e seus aliados. Seria ainda uma intervenção provavelmente mais longa, além da dificuldade de envolver países como Jordânia, Grécia e Turquia na operação, como bases mais próximas à Síria. Há ainda o problema da artilharia não estar concentrada em bases específicas, mas espalhada pelo território, dificultando o ataque (STRATFOR, 2013).

A terceira e mais complicada e custosa alternativa seria a de destruir todo o arsenal químico do regime de Assad, impossibilitando completamente seu uso futuro. Essa estratégia requereria tropas em solo sírio, e contaria ainda com o desafio da destruição das armas, tarefa bastante difícil de ser executada, podendo ter sérios efeitos, ao passo que enquanto parte do material é destruído, parte é lançado à atmosfera e, considerando que muitos depósitos situam-se perto de cidades e áreas residenciais, parte da população poderia ser atingida (STRATFOR, 2013). 
$145 \mid$ InterAção

Chemical weapons are difficult to destroy completely. The most common method is incineration at very high temperatures over a sustained period of time in a constant system. Munitions used by the military almost never reproduce these effects, especially the ones designed to penetrate a hardened structure. Another problem is the sheer volume of material. Estimates put Syrian stockpiles in the hundreds of tons of various types. [...] The most likely result of strikes on hardened facilities holding chemical weapons is the destruction of some of the material and the release of some into the atmosphere while the rest remains protect by the collapsed structure in rubble. In other words, a strike would succeed in destroying the material only partially while potentially causing collateral damage (many of the facilities are near populated areas) and only temporarily denying the regime the use of any remaining stockpiles (STRATFOR, 2013).

Além da dificuldade da destruição do arsenal químico, uma intervenção militar dessa magnitude aproximar-se-ia de uma real invasão da Síria, dada a enorme necessidade de forças em solo. Mais do que isso, um ataque dessa grandeza acarretaria muito provavelmente no fim do regime de Assad (STRATFOR, 2013). A deposição de Assad faria surgir a necessidade de 
146 | InterAção

esforços americanos e de seus aliados no sentido de reorganização política do país, implicando em uma ação prolongada no tempo, justamente o maior receio dos americanos.

Mais do que as dificuldades estratégicas, como vimos acima, existe a questão do real objetivo da operação militar. Se o objetivo, como na primeira opção, for meramente punitivo, mantendo o regime e parte de seu arsenal militar, os Estados Unidos correm o risco de empenhar esforços econômicos e humanos em uma operação que pode não trazer resultados efetivos. Por outro lado, se a ação militar americana resultar na deposição de Assad, como nos traz o terceiro cenário estratégico analisado, os Estados Unidos encontrar-se-iam novamente envolvidos em uma longa operação que, a exemplo do Iraque, apresentaria inúmeras dificuldades e uma grande probabilidade de fracasso, além do dilema de retirada das tropas americanas do país posteriormente.

This is the option with the greatest potential for bogging down forces in an occupation. Chemical weapons are hard to deal with and require time to destroy and longer still to move elsewhere and destroy. Either way, a standing army will find itself in Syria 
$147 \mid$ InterAção

for at least a few months. Any form of mission creep into nation restabilization or building extends the timeline indefinitely. Even if the invasion went well, as it did in Iraq, the occupation period creates an opening for guerrilla or insurgent warfare waged by the fallen regime, Islamist extremists, disenfranchised rebels or all of the above (STRATFOR, 2013).

Outro problema sistêmico em relação à intervenção americana na Síria tem caráter ideológico. Parte da inação dos Estados Unidos frente à Primavera Árabe em geral pode ser explicada pelo fato de que, apesar de sustentar discursos em favor da liberdade e pródemocracia, os Estados Unidos, em sua história recente, têm dado suporte à diversos países do Oriente Médio governados por regimes autoritários.

Logo depois do final da Segunda Guerra Mundial, os Estados Unidos tinham sua política externa para o Oriente Médio fundada em seis grandes estratégias: evitar a expansão da influência soviética, garantir o acesso do ocidente ao petróleo, garantir a resolução pacífica de conflitos e a manutenção de um balanço de poder regional, promover Estados estáveis e favoráveis ao 
ocidente, preservar a independência e a integridade do Estado de Israel, e proteger os mares, linhas de comunicação e outras formas de conexão dos Estados Unidos e Europa com a Ásia (GELVIN, 2012).

Authoritarian regimes were useful in achieving all these goals. For example, American policy makers believed only strong, authoritarian regimes could bring about the rapid economic development necessary to prevent their populations from "going communist". Only strong, authoritarian regimes, such as that in Egypt could sign peace treaties with Israel in the face of popular opposition to those treaties. And only strong, authoritarian regimes that maintained a regional balance of power could ensure uninterrupted supply of oil to the United States and its allies (GELVIN, 2012).

Com o final da Guerra Fria, com exceção da contenção da expansão soviética, os Estados Unidos mantiveram em grande medida suas estratégias para região e, por conseguinte, também o apoio a regimes autoritários. Durante a War on Terror, os Estados Unidos tiveram o apoio de países como o Egito, Iêmen, e a Líbia. Mesmo depois de 2003, com o lançamento da "freedom agenda", os Estados Unidos continuaram contando com o 
$149 \mid$ InterAção

suporte desses países, com alguns dos regimes mais repressivos do Oriente Médio.

Em uma pesquisa conduzida pelo professor do Department of Peace and Conflict da Universidade de Uppsala, na Suécia, Timo Kivimaki, foram analisadas as reações americanas a movimentos pró-democracia na região do Oriente Médio e o norte da África entre 1946 e 2010. Kivimaki concluiu que existe uma relação positiva entre os Estados Unidos e regimes autocráticos. Favorável à estabilidade, os Estados Unidos nesse período, de forma geral, responderam com sanções negativas aos países onde emergiam qualquer tipo de alteração da estabilidade, seja por levantes pró-democracia ou violentas ofensivas pela manutenção do regime por parte dos governos (KIVIMAKI, 2010).

A closer study of polity profiles reveals that the United States has generally supported countries that are stable. This is understandable, considering U.S. oil interests in the Middle East. However, many of the regimes demonized in the Western Media are not nearly as autocratic as are some of the most stable U.S. allies. In fact, even the much-condemned Iranian and Sudanese governments 


$$
150 \text { | InterAção }
$$

are less autocratic than the average Muslim regime supported by Washington. [...] A crude analysis of U.S. use of carrots and sticks reveals clearly how much American policy is based on negative rather than positive sanctions as a reaction to positive and negative changes (KIVIMAKI, 2010).

Essa estreita relação dos Estados Unidos com regimes autoritários explica em parte a relutância do envolvimento da política externa americana no conflito. Apesar da retórica pró-democracia, durante muitos anos o suporte a regimes autoritários foram a maneira encontrada pelos Estados Unidos de garantir a tão necessária estabilidadena região. Daí surge parte do paradoxo que resulta na falta de uma postura clara dos Estados Unidos em relação à Primavera Árabe.

\section{III - RATIONAL COOPERATIONE O VALOR DOS REGIMES INTERNACIONAIS: UMA ANÁLISE DA POLÍTICA EXTERNA NORTE- AMERICANA PARA A CRISE NA SÍRIA}

Ao anunciar o envolvimento militar americano no final do mês de agosto, em virtude da confirmação do ataque aos rebeldes fazendo uso de armas químicas, Obama preferiu ter a escolha pelo envolvimento 
$151 \mid$ InterAção

legitimada pelo Congresso americano. Em constante diálogo com o governo russo, e com a retirada do apoio do Reino Unido no dia 29 de agosto, entretanto, no dia 11 de setembro, em um discurso proferido à nação, Barack Obama pediu que o Congresso adiasse a votação sobre o envolvimento militar americano, deixando clara sua predileção pela via diplomática para resolver a questão das armas químicas na Síria.

Está marcada para dia 22 de janeiro a conferência de Geneva II, que pretende reunir pela primeira vez o governo de Assad com representantes dos rebeldes, almejando alcançar um acordo sobre a transição do governo, além de outros elementos traçados pela conferência que reuniu potências ocidentais em Junho deste ano, em Genebra7. A proposta de Putin que fez com que Obama fizesse seu pedido ao Congresso em setembro

\footnotetext{
7 A conferência de Genebra I reuniu representantes da ONU, Liga Árabe, União Europeia, China, França, Rússia, Reino Unido e os Estados Unidos. Também a Turquia, Iraque, Kuwait e Qatar, representando diversos corpos ministeriais árabes. Como resultado da conferência foi emitido o Genneva Communique, que versa sobre os pressupostos de uma estratégia para uma transição pacífica entre governos, que envolve a implementação de um governo de transição, garantia de eleições, etc. 0 documento ressalta ainda a importância da participação das mulheres nesse processo.
} 
consiste sumariamente na entrega pelo regime de Assad, de forma pacífica e voluntária, de seu arsenal químico.

Chama a atenção a busca dos Estados Unidos pela via multilateral e a tentativa de esgotamento das vias diplomáticas de resolução da crise na Síria; a tentativa, que pode ou não se concretizar, pela via institucional, procurando evitar, através dos meios que forem possíveis, o envolvimento militar direto e unilateral dos Estados Unidos. A importância desta pesquisa independe, portanto, em grande medida do desfecho da atuação internacional em face da crise na Síria. A busca incansável do governo de Obama por saídas que não a unilateral destoa dos últimos anos de política externa americana para o Oriente Médio e tem relevância incontestável para o estudo das relações internacionais contemporâneas.

Many of you have asked why not leave this to other countries, or seek solutions short of force. And several people wrote to me we should not be the world's policemen. I agree and I have a deeply held preference for peaceful solutions. Over the last two years my administration has tried diplomacy and sanctions, warnings and negotiations. But chemical weapons were still used by the Assad regime. However, over the last few 
153 InterAção

days we have seen some encouraging signs. In part because of the credible threat of the US military action, as well as constructive talks that I've had with president Putin, the Russian government has indicated the willingness to join with the international community in pushing Assad to give up his chemical weapons. The Assad regime has now admitted it has these weapons, even said they would join the chemical weapons convention, which prohibits their use. It's too early to tell whether this offer will succeed, and any agreement must verify that the Assad regime keeps its commitments. But this initiative has the potential to remove the threat of chemical weapons without the use of force, particularly because Russia is one of Assad's strongest allies. I have therefore asked the leaders of congress to postpone the vote to authorize the use of force, while we pursue this diplomatic path. I'm sending secretary of state John Kerry to meet his Russian counterpart on Thursday, and I will continue my own discussions with president Putin. I've spoken to the leaders of two of our closest allies, France and the United Kingdom, and we will work together in consultation with Russia and China, to put forward a resolution at the UN's security council requiring Assad to give up his chemical weapons and to ultimately destroy them under international control. We'll also give UN inspectors 


\section{$154 \mid$ InterAção}

the opportunity to report their findings about what happened on august $21^{\text {st }}$. And we will continue to rally support from allies from Europe to the Americas, from Asia to the Middle East, who agree on the need for action. Meanwhile, I have ordered our military to maintain their current posture, to keep the pressure on Assad and to be in a position to respond if diplomacy fails (OBAMA, 2013) ${ }^{8}$.

8 "Muitos de vocês têm perguntado por que não deixar isso para outros países, ou procurar por soluções que não impliquem em uma grande mobilização de forças. $E$ muitas pessoas me escreveram que nós não devemos ser a "polícia" do mundo. Eu concordo, e tenho uma profunda preferência por soluções pacíficas. Nos últimos dois anos, minha administração tentou a diplomacia e sanções, avisos e negociações. Ainda assim, armas químicas foram utilizadas pelo regime de Assad. Entretanto, nos últimos dias, nós percebemos alguns sinais encorajadores. Em parte por causa da real ameaça de uma ação militar americana, e também por causa de construtivas conversas que tive com o presidente Putin, o governo russo indicou sua vontade de juntar-se à comunidade internacional em sua tentativa de pressionar Assad para que entregue suas armas químicas. 0 governo de Assad agora admitiu que possui essas armas, e indicou ainda que assinariam a convenção de armas químicas, que proíbe 0 seu uso. Ainda é muito cedo para sabermos se a oferta vai ser bem sucedida ou não, e qualquer acordo deve ser capaz de verificar se o regime de Assad fará jus a seus compromissos. Essa iniciativa, entretanto, tem o potencial de remover a ameaça do uso de armas químicas sem 0 uso de força, particularmente porque 0 regime de Assad tem na Rússia um de seus principais aliados. Eu pedi portanto aos membros do Congresso que adiem a votação para autorizar o uso da força, enquanto nós seguimos por esse caminho diplomático. Eu estou enviando o Secretário de Estado John Kerry para encontrar o Secretário de Estado russo na quinta-feira, e eu vou continuar minhas próprias discussões com o presidente Putin. Eu conversei com os líderes de dois dos nossos maiores aliados, França e Reino Unido, e nós vamos trabalhar juntos, em parceria com Rússia e China, para encaminhar uma resolução ao Conselho de Segurança das Nações Unidas pedindo a Assad que entregue suas armas químicas para que sejam, enfim, destruídas sob controle internacional. Nós daremos ainda a oportunidade aos inspetores da ONU para que relatem suas descobertas sobre o que aconteceu no dia 21 de agosto. E continuaremos a buscar suporte em nossos aliados da Europa às Américas, da Ásia ao Oriente Médio, que concordem com a necessidade de ação. Enquanto isso, eu pedi ao nosso exército 
$155 \mid$ InterAção

A cooperação é interessante objeto de estudo nos dias de hoje sumariamente porque cada vez menos parece haver lugar para grandes conflitos entre países no sistema internacional contemporâneo. Apesar do acesso de diversos países a tecnologias que há algumas décadas eram restritas fundamentalmente aos dois grandes polos de poder que caracterizaram o mundo bipolar, a verdade é que a intensificação do globalismo ${ }^{9}$ tornou demasiado custosas quaisquer grandes ofensivas militares de um Estado em relação a outro. Além dos custos de ações militares aos Estados, os novos grandes desafios da agenda internacional como o terrorismo, as questões ambientais, a questão dos direitos humanos, muitas vezes delegam ao poder militar um papel secundário, dada sua incapacidade de responder a esses temas. A partir da Guerra Fria, observa-se um padrão de conflitos que migra

que mantenha sua postura atual, mantendo a pressão ao regime de Assad e para que esteja em condições de responder caso a diplomacia venha a falhar" (tradução nossa).

${ }^{9}$ Dentro da teoria da Interdependência Complexa, o fenômeno do globalismo é compreendido como uma condição, um "estado do mundo", que pode variar de intensidade com o passar do tempo. Nas palavras dos autores:"We define globalism as a state of the world involving networks of interdependence at multicontinental distances, linked through flows and influences of capital and goods, information and ideas, people and force, as well as environmentally and biologically relevant substances (such as acid rain or pathogens). Globalization and deglobalization refer to the increase or decline of globalism" (KEOHANE; NYE, 1984). 
dos conflitos entre Estados para conflitos que tomam lugar dentro das fronteiras nacionais. São conflitos motivados por questões étnicas, religiosas, etc. (NYE, 2009).

\begin{abstract}
As guerras maiores tornaram-se menos prováveis depois do fim da Guerra Fria, mas os conflitos regionais e internos persistem e sempre haverá pressões para que outros Estados e instituições internacionais intervenham. Dos 116 conflitos que ocorreram entre o fim da Guerra Fria e o início do novo século, 89 foram puramente intraestatais (guerras civis) e outros 20 foram interestatais com intervenção estrangeira. Mas de 80 protagonistas estatais estiveram envolvidos, assim como duas organizações regionais e mais de 200 partidos não governamentais (NYE, 2009).
\end{abstract}

A cooperação, durante muitos anos, foi explicada dentro das relações internacionais a partir de uma natureza dos Estados idealizada pela teoria liberal, ou ainda deixada de lado pelos realistas, que, ao presumirem os Estados como indivíduos racionais, não encontravam espaço para a cooperação em sua teoria, a não ser como meio para se alcançar um objetivo já bem definido em termos de seu interesse. Keohane e Nye (1977) conseguem superar essa barreira explicando o fenômeno da 
$157 \mid$ InterAção

cooperação a partir de Estados entendidos como indivíduos egoístas e racionais.

A cooperação, dentro da teoria arquitetada pelos autores, não só é viável, como também, em algumas situações, é a melhor política a ser buscada pelos Estados enquanto atores racionais. A busca ao multilateralismo pelos Estados Unidos frente ao conflito civil na Síria é, talvez, o mais pujante exemplo da atualidade da cooperação como instrumento racional. Iniciado com os levantes da chamada Primavera Árabe, o conflito na Síria tomou enormes proporções, tanto em termos de duração como pelo elevado teor de violência empregado contra a oposição.

Enquanto indivíduos racionais, ocorre que os Estados muitas vezes, mesmo tendo interesses comuns, falham ao tentar cooperar, em decorrência de sua própria natureza racional e também da natureza do sistema internacional em si. A ausência de uma autoridade superior capaz de coordenar as políticas entre os Estados impõe alguns problemas à cooperação. Os regimes internacionais dentro da teoria de Nye e Keohane têm a 
158 | InterAção

função de superar as dificuldades do sistema internacional anárquico, facilitando a cooperação. Esses cumprem seu papel adequando o sistema internacional aos pressupostos do Teorema de Coase ${ }^{10}$, ou seja, criando uma base legal dentro do sistema internacional, democratizando o acesso à informação e reduzindo os custos de transação.

Apesar da dificuldade de sua criação, uma vez consolidados, os regimes internacionais passam a ter valor a seus membros, na medida em que facilitam a cooperação (KEOHANE, 1984). Nesse sentido, funcionam como um conjunto de normas e procedimentos a serem seguidos, criando parâmetros comportamentais e facilitando o acesso dos Estados às informações necessárias. Dentro desse contexto, ações que violem o panorama dos regimes são mais custosas, ao mesmo tempo em que ações que respeitem essas normas e princípios estabelecidos têm menos custos aos Estados. Os regimes internacionais, que

\footnotetext{
${ }^{10} \mathrm{Em}$ 1960, Richard Coase desenvolveu uma tese contrariando a ideia das teorias de falência dos mercados que alegavam que em determinadas situações, "mutually beneficial agreements" não tomavam lugar devido a falhas no sistema. Coase escreveu então que esses acordos eram sim possíveis, desde que estivessem presentes três grandes carcaterísticas: legal framework, zero transaction costs, perfect information. Keohane e Nye colocam então que a grande função dos regimes internacionais é a de permitir que esses acordos sejam feitos, possibilitando a cooperação, adequando o sistema internacional aos três pressupostos de Coase.
} 
$159 \mid$ InterAção

podem ser institucionalizados ou não, carregam ainda a importante função de funcionar como fóruns, capazes de aproximar governos e definir prioridades de agenda.

Dentro do sistema internacional, como lembram Keohane e Nye, os Estados estão sujeitos a um conjunto de valores e princípios, que pautam suas ações, auxiliando na definição de prioridades e na tomada de decisões. As ações dos Estados, ou mesmo a falta destas, refletem em sua reputação dentro do sistema de Estados. Como vimos, quando Obama assumiu o governo americano em 2009, tinha como uma de suas principais promessas melhorar a imagem dos Estados Unidos no mundo. Essa é a primeira grande causa que estudamos aqui capaz de explicar a opção americana pela cooperação.

Quando ficaram confirmados os ataques com armas químicas à população síria, o governo americano, como grande defensor das liberdades individuais, ficou moralmente obrigado a agir. Mais do que seu histórico envolvimento com o Oriente Médio e a notável preocupação do governo americano com a eliminação das armas de destruição em massa em todo o mundo, Obama 


$$
160 \text { | InterAção }
$$

havia definido o uso de armas químicas como a "red line" do governo sírio. Uma ação militar unilateral, entretanto, prejudicaria ainda mais a já desgastada imagem dos Estados Unidos e sua ingerência no Oriente Médio.
A via multilateral também mostrou-se viável frente às dificuldades internas que enfrenta o país atualmente. Como vimos no início deste artigo, a população americana é em sua maioria veementemente contrária à intervenção direta na Síria, fundamentalmente em virtude de um pensamento bastante geral entre os americanos de que os EUA precisam resolver seus problemas internos se quiserem uma projeção eficaz internacionalmente. Ainda em fase de recuperação de uma grave crise econômica, é fácil supormos que qualquer projeto de intervenção que conte com grandes investimentos por um período de tempo que pode ser indefinido não conta com o apoio da população.
Outro empecilho à intervenção americana é a dificuldade da ação militar no país em si. No subcapítulo anterior, analisamos as três formas possíveis de intervenção militar, e vimos que todas elas implicam custos ao governo americano, diversos problemas em 
$161 \mid$ InterAção

virtude da dificuldade de destruir armas químicas, o grande risco de efeitos colaterais, atingindo parte da população, além da possibilidade sempre presente de a intervenção não alcançar os resultados esperados. Existe ainda o não menos importante problema de os Estados Unidos ajudarem na derrubada de um governo autoritário enquanto mantêm como aliados outros países da região com regimes semelhantes ao do governo de Assad.

Amparados pelos regimes internacionais, os Estados Unidos foram capazes de articular uma política que fizesse frente às violações do governo sírio dividindo os custos de ação com outros atores do sistema internacional. A opção americana pelo multilateralismo procura restaurar a imagem internacional do país, que busca nos organismos internacionais a legitimação para suas políticas. Além disso, evita o tão temido envolvimento americano em mais um longo conflito no Oriente Médio, tudo isso sem fugir da responsabilidade de punir uma ação que foge dos parâmetros comportamentais estabelecidos a partir dos princípios e valores que pautam as relações entre os Estados. 
162 | InterAção

\section{CONSIDERAÇÕES FINAIS}

Por vezes, os Estados nacionais entendidos como indivíduos egoístas e racionais inseridos em um sistema cuja grande característica é a ausência de qualquer organismo superior à sua autoridade enquanto soberano, deparam-se com situações em que a cooperação surge como alternativa mais viável. Seja por interesse ou pela própria natureza do objetivo que se busca alcançar, entendemos que a cooperação no século XXI deve ser parte da estratégia de qualquer Estado Nacional que busque desempenhar um papel de relevância dentro do sistema internacional.

O século XXI inicia-se com algumas certezas. Ainda que muitos autores discordem sobre conceitos fundamentais dentro das relações internacionais como a natureza do poder ou a própria forma como se configuram tradicionalmente as relações entre os Estados em termos de uni, multi ou bipolaridade, é certo que esse século traz inúmeros desafios que demandam ações 
$163 \mid$ InterAção

conjuntas entre os Estados. Seja pela globalização e as consequências da democratização do acesso à tecnologia e, em grande medida também à informação, que gera ameaças como o terrorismo transnacional ou ainda problemas como a questão ambiental, o que se verifica hoje é um sistema em que as ameaças dificilmente concentram-se dentro das fronteiras dos Estados.

A cooperação, além de necessária em inúmeras situações, pode e deve fazer parte de uma estratégia racional dos Estados. O conceito de Rational Cooperation aborda a cooperação como uma forma de viabilizar políticas que unilateralmente seriam inviáveis ou ainda demasiado custosas. Em um sistema caracterizado pela interdependência complexa que une países de diversas formas e a minimização da importância do poder militar, a coordenação de políticas é sem dúvida fundamental instrumento para a realização dos interesses dos Estados.

Os Estados Unidos, que há menos de 30 anos contavam com uma posição de inegável superioridade em relação a qualquer outro Estado, foram também atingidos pelas drásticas mudanças que sofreu o sistema 
164 | InterAção

internacional. Entre a difusão tecnológica, avanço econômico e também militar de outros países, a completa descaracterização das grandes ameaças aos Estados como eram conhecidas há meio século, além das dificuldades internas que vêm atravessando o país principalmente na última década, os Estados Unidos, ainda que indubitavelmente ocupem a posição mais importante dentro do sistema de Estados, tiveram relativizada sua capacidade de influenciar outros atores e moldar o sistema de forma a obter os resultados desejados.

A National Security Strategy, encaminhada ao Congresso em 2010, parece fazer uma apurada leitura dessa reorganização do sistema internacional, revendo o papel dos Estados Unidos dentro desse novo contexto. O grande enfoque da nova estratégia está nas alianças dos Estados Unidos e sua atuação em fóruns internacionais, além da retomada de preocupações da estratégia do antigo governo democrata, com o papel dos Estados Unidos como vetor da paz e segurança internacionais através da difusão de valores ocidentais. A NSS 2010 reconhece ainda a mudança na natureza dos grandes 
$165 \mid$ InterAção

desafios globais, e vê no multilateralismo sua grande estratégia para alcançar os interesses do país.

Mas diante de tantas mudanças, a principal delas ainda parece ser a nova abordagem do país em relação ao Oriente Médio. A NSS 2010 consagra as grandes promessas de mudança da campanha de Barack Obama em relação à atuação do país frente àquela região. Em face de pressões domésticas e também da sociedade internacional, a NSS 2010 tem como um de seus grandes focos o disengagement do Oriente Médio, voltando-se a política externa americana cada vez mais ao eixo ÁsiaPacífico, com o fortalecimento da quinta tropa. Apesar do controverso envio de soldados ao Afeganistão no início de 2009, o mandato de Obama foi marcado por sinais bastante claros de que o país não pretende manter seu envolvimento com a região na forma como está.

O conflito civil na Síria da maneira como se desenrolou fez chocar o "moral duty" americano em relação à defesa dos valores ocidentais, marcadamente a democracia e o respeito aos direitos humanos, com a obstinação da política americana em relação a sua "hands- 
166 | InterAção

off policy". A dificuldade de uma intervenção militar direta ultrapassa ainda o problema de ir contra ao que pretende o governo americano em relação à região. Como vimos, a opinião pública do país é fortemente contrária a um envolvimento direto dos Estados Unidos e acredita ainda que o país não tem a obrigação e não deve se envolver em conflitos internacionais que fujam da sua alçada de interesses diretos. Os receios da opinião pública americana são explicados, em parte, pelo insucesso das intervenções americanas no Afeganistão e no Iraque, e são, em parte, compartilhados pela sociedade internacional e em especial pela população do Oriente Médio, onde na primeira década desse século viu-se o antiamericanismo tomar grandes proporções.

Mais do que alimentar a oposição da opinião pública em relação ao conflito, especialistas nos trazem que o problema das dívidas interna e externa estão fazendo com que o país não alcance o crescimento que poderia ter, dados os seus potenciais, prejudicando sua projeção internacional em termos de poder de barganha, deteriorando ainda a credibilidade da organização econômica internacional por ele idealizada. Além disso, a 
$167 \mid$ InterAção

elevada dificuldade de uma possível ação militar no país somada ao problema da contradição ideológica de os Estados Unidos ajudarem a derrubar um regime de natureza semelhante à de muitos de seus maiores aliados na região como a Arábia Saudita, por exemplo, tornam demasiado custosas quaisquer iniciativas militares diretas unilaterais na região.

Apoiada em uma série de valores e padrões morais de comportamento, a sociedade internacional não pode entretanto deixar de agir em situações extremas como é o caso da Síria, correndo suas grandes potências que garantem a continuidade da ordem internacional um grande risco de terem suas reputações, e como consequência disso, a reputação do próprio sistema, comprometidas. Ainda que não se fale em hegemonia, os Estados Unidos no século XXI carregam ainda fundamental papel dentro do sistema internacional, importando suas escolhas e decisões mais do que a de quaisquer outras potências, em especial quando a pauta é Oriente Médio. Como forma de conciliar a necessidade de agir com a dificuldade de agir, os Estados Unidos organizaram sua política externa para o conflito na Síria 
168 | InterAção

sobre as estruturas dos regimes internacionais, apoiandose e buscando legitimidade no multilateralismo, optando pela cooperação como forma de dividir os custos de ação, facilitando ações necessárias que seriam muito custosas se perseguidas unilateralmente. É a figura da rational cooperation.

Conforme já procuramos deixar claro, o desenrolar da atuação americana ainda segue em aberto. Ao concluirmos esta pesquisa o que se tem de previsão futura é a reunião dos líderes tanto de potências ocidentais quanto do governo de Assad, e líderes da oposição na Síria, para que seja discutida uma transição pacífica no país, a ocorrer em Janeiro de 2014. Está em andamento ainda o plano de entrega das armas químicas do governo de Assad arquitetado pelo governo Russo que conta hoje com o apoio americano. Ainda que possa ocorrer, as chances de uma intervenção militar unilateral americana são hoje bastante remotas. Passados quase quatro meses dos ataques do governo Sírio à população com a utilização de armas químicas, parece a sociedade internacional ter perdido o timing para uma retaliação efetiva. Ainda que venha a tomar lugar uma ação direta 
169 InterAção

americana, entretanto, tem valor nossa investigação à medida em que a mera busca pela legitimação internacional por parte dos Estados Unidos já destoa do que vinha sido feito pela política externa do país na última década.

A cooperação em situações de interdependência complexa, como colocam Keohane e Nye, é parte de uma estratégia racional dos Estados. Longe de idealizar a natureza desses atores como acusam os autores de fazerem os institucionalistas, explicam eles a rational cooperation como formas de coordenar políticas objetivando contornar a discórdia, característica primeira do sistema internacional. Para alcançar essa cooperação, os Estados amparam-se nos regimes internacionais. Instituições que, apesar de em uma análise superficial limitar a soberania dos Estados, são de seu próprio interesse à medida em que viabilizam a cooperação a partir de mecanismos que superam as dificuldades que a própria natureza do sistema internacional impõe à cooperação.

\section{REFERÊNCIAS}


170 | InterAção

ACNUDH. Especial ONU Brasil - Síria. Disponível em: <http://www.onu.org.br/siria/>. Acesso em: 12 jul. 2013.

ALJAZEERA. A possible U.S. attack on Syria: causes and consequences. 15 set. 2013. Disponível em:

<http://studies.aljazeera.net/en/ positionpapers/2013/09 /201391511491236484.htm>. Acesso em: 12 nov. 2013.

FRIEDMAN, G. Strategy, ideology and the close of the Syrian crisis. Stratfor, 17 set. 2013. Disponível em: <http://www.stratfor.com/weekly/strategy-ideologyand-close-syrian-crisis>. Acesso em: 12 out. 2013.

GELVIN, J. L. The Arab uprisings: What everyone needs to know. New York: Oxford University Press, 2012.

HAASS, R. N. Foreign Policy Begins at Home: The case for putting America's house in order. New York: Basic Books, 2013. 195 p.

INDYK, M.; LIEBERTHAL, K.; O'HANLON, M. E. Bending history: Barack Obama's foreign policy. Washington: The Brookings Institution, 2012.

KEOHANE, R. O. After Hegemony: Cooperation and Discord in the World Political Economy. New Jersey: Princeton University Press, 1984. 290 p. 
$171 \mid$ InterAção

KEOHANE, R. O.; NYE, J. S. Power and Interdependence. Boston: Little, Brown and Company, 1977.

KIVIMAKI, T. Democracy, autocrats and U.S. policies in the Middle East. Middle East Policy, Vol. 19, n. 1, pp. 6471, spring, 2012. Disponível em:

<http://onlinelibrary.wiley.com/doi/10.1111/j.14754967.2012.00523.x/full>. Acesso em: 19 set. 2013.

LANDLER, M.; THEE-BRENAN, M. Survey reveals scant backing for Syria strike. The New York Times, 9 set. 2013. Disponível em:

<http://www.nytimes.com/2013/09/10/world/middlee ast/poll-majority-of-americans-oppose-militarystrike.html>. Acesso em: 10 out. 2013.

NASR, V. The Dispensable Nation: American Foreign Policy in Retreat. New York: Random House, 2013. 300 p.

NYE, J. S. Cooperação e conflito nas relações

internacionais. Trad. Henrique Amat Rêgo Monteiro. São Paulo: Editora Gente, 2009.

NYE, J. S. O futuro do poder.São Paulo: Benvirá, 2012. 333 p.

OBAMA, B. Speech on postponing the Congressional vote on Syria strike. 11 set. 2013. Washington. D. C. 
Disponível em: <http://www.bbc.co.uk/news/world24051698>. Acesso em: 23 nov. 2013.

RATNESAR, $\mathrm{R}$. There is nothing foreign about foreign policy. Bloomberg Businessweek, 24 out. 2012.

Disponível em:

<http://www.businessweek.com/articles/2012-10-

24/theres-nothing-foreign-about-foreign-policy>. Acesso em: 22 nov. 2013.

SANGER, D. E. For Obama, an evolving doctrine on foreign policy. The New York Times, 24 set. 2013.

Disponível em:

<http://www.nytimes.com/2013/09/25/world/middlee ast/obamas-evolving-doctrine.html?_r=0>. Acesso em: 22 out. 2013.

SEITENFUS, R. Relações Internacionais. Barueri: Manole, 2004.

SSRS of Media. American views on Syrian strike.

Disponível em:

<http://topics.nytimes.com/top/reference/timestopics/s ubjects/n/newyorktimes-pollwatch/index.html? offset=10\&s=newest $>$. Acesso em: 10 out. 2013.

STRATFOR. Syria: a comprehensive look at the options for intervention. 27 ago. 2013. Disponível em: <http://www.stratfor.com/analysis/syria- 
$173 \mid$ InterAção

comprehensive-look-options-intervention>. Acesso em: 30 set. 2013.

VILLA, R. A. Opinião pública, mídia e relações

internacionais. Revista de Sociologia Política. 2003.

WORLD BANK. GDP growth (annual \%). Disponível em: <http:/ / data.worldbank.org/indicator/NY.GDP.MKTP.K D.ZG?order=wbapi_data_value_2009\%20wbapi_data_val ue\%20wbapi_data_value-first\&sort=asc $>$. Acesso em: 23 set. 2013. 